Pesq. Vet. Bras. 29(3):258-262, março 2009

\title{
Implante de cartilagem auricular autóloga no reparo de desvio de pênis de bovinos ${ }^{1}$
}

\author{
Duvaldo Eurides ${ }^{2}$, Luiz A.F. Silva ${ }^{3}$, Carlos R. Daleck ${ }^{4}$, Maria C.S. Fioravanti ${ }^{3}$, \\ Gentil F. Gonçalves ${ }^{5}$, Olizio C. Silva ${ }^{3}$ e Andrigo B. Nadri6 \\ ABSTRACT.- Eurides D., Silva L.A.F., Daleck C.R., Fioravanti M.C., Gonçalves G.F., \\ Silva O.F. \& Nadri A.B. 2009. [Implantation of the autologous auricular cartilagem in \\ the repair of penile deviation in cattle.] Implante de cartilagem auricular autóloga no \\ reparo de desvio de pênis de bovinos. Pesquisa Veterinária Brasileira 29(3):258-262. \\ Faculdade de Medicina Veterinária, Universidade Federal de Uberlândia, Av. Pará 1720, \\ Campus Umuarama, Uberlândia, MG 38400-902, Brazil. E-mail: duvaldo @ufu.br \\ Eighteen 18 to 24-month-old mixed breed bullocks were submitted to removal of the \\ apical ligament of the penis to induce penile deviation. After 60 days from the surgery the \\ steers were put together with cows in heat. A ventral and right lateral penis deviation \\ leading to incapacity to copulate was observed. The bullocks were then submitted to an \\ autolgous transplant of a cartilage segment from the ear pinna placed on top of the tunica \\ albuginea, replacing the penile ligament apical tha had been removed. The implanted \\ material was well tolerated; histologically with only infiltration few mononuclear cells, \\ polymorpho nucleated cells and giant cells, and fibrosis, which caused strong adherence \\ and provided ability to sustain the free penile extremity. The bullocks that were cows in \\ heat did not show any degree of penile deviation nor any change in sexual behavior. The \\ surgical method described here was shown to be satisfactory as to be indicated for \\ correction of ventral and right lateral penile deviation in bullocks.
}

INDEX TERMS: Cattle, surgery, penile deviation repair, implant.

RESUMO.- Dezoito novilhos de diferentes raças, com idade de 18-24 meses foram submetidos a remoção do ligamento apical para ocasionar desvio de pênis. Decorridos 60 dias os animais foram colocados em presença de fêmeas em estro, sendo verificado desvio ventral e lateral

\footnotetext{
${ }^{1}$ Recebido em 9 de outubro de 2008.

Aceito para publicação em 6 de novembro de 2008.

2 Faculdade de Medicina Veterinária, Universidade Federal de Uberlândia, Av. Pará 1720, Campus Umuarama, Uberlândia, MG 38400902, Brasil. *Autor para correspondência: duvaldo@ufu.br

${ }^{3}$ Departamento de Medicina Veterinária, Escola de Veterinária, Universidade Federal de Goiás (UFG), Rodovia Goiânia-Nova Veneza Km 0, Campus II, Goiânia, GO, 74001-970, Brasil.

${ }^{4}$ Departamento de Clínica e Cirurgia Veterinária, Faculdade de Medicina Veterinária, Universidade Estadual Paulista (Unesp), Via de Acesso Prof. Paulo Donato Castellani s/n, Jaboticabal, SP14884-900, Brasil.

${ }^{5}$ Curso de Medicina Veterinária, Universidade Paranaense (Unipar), Campus Sede , Praça Mascarenhas Morais, Umuarama, PR 87502210, Brasil.

${ }^{6}$ Escola de Medicina Veterinária e Zootécnia, Universidade Federal de Tocantins, BR-153 Km 112, Araguaína, TO 7784-970, Brasil.
}

direito do pênis, com incapacitade de cópula. Os animais foram submetidos ao transplante autólgo de um segmento da cartilagem do pavilhão auricular, sobre a túnica albugínea, substituindo o ligamento apical do pênis removido. Os bovinos quando em presença de fêmeas em estro não apresentaram desvio de pênis e alteração do comportamento sexual. Notou-se a presença de poucas células mononucleares, polimorfonucleares e células gigantes e formação de tecido conjuntivo fibroso, ocasionando aderências resistentes e capacidade de sustentar a extremidade livre do pênis. O método cirúrgico mostrou-se eficiente para corrigir desvios ventral e lateral de pênis de bovinos.

TERMOS DE INDEXAÇÃO: Bovinos, cirurgia, correção de desvio peniano, implante.

\section{INTRODUÇÃO}

O ligamento apical de bovinos da raça Nelore não apresenta uma origem definida. Sua formação se dá pela face esquerda do pênis ao longo da túnica albugínea, chegan- 
do até a face esquerda da glande próximo ao sulco uretral, com menor incidência envolvendo as faces esquerda e direita. Na glande o ligamento se abre em forma de leque acompanhando o trajeto do sulco uretral e insere-se a $1,99 \mathrm{~cm}$ em média do processo uretral, também com a mesma morfologia, encontra-se aderido a túnica albugínea na face esquerda.. Nessa face sua espessura é maior que na face direita e encontra-se separado por tecido conjuntivo frouxo da túnica albugínea (Eurides et al. 1998).

Três formas de desvio foram descritas em touros sendo o mais comum em espiral, seguido do ventral e em forma de "S" que é o mais raro (Roberts 1979, Mobini \& Walker 1983). O desvio ventral ocorre em touros jovens (Walker 1980). A ocorrência tem sido descrita em várias raças leiteiras e as destinadas a produção de carne, com a maioria dos casos em bovinos da pecuária de corte, particularmente o Hereford (Arthur 1979). No desvio ventral o ligamento apical é insuficientemente desenvolvido para conter o pênis ereto durante a ereção e o em espiral é produzido quando o ligamento escorrega para o lado esquerdo do pênis durante o ingurgitamento (Walker 1980). A secção do ligamento apical de touros acarreta o desvio ventral e desvio lateral direito, durante a ereção do pênis (Ashdown \& Perarson 1971), fato também verificado por Eurides et al. (1992) quando removeram o ligamento apical no preparo de rufiões bovinos.

Técnicas cirúrgicas foram descritas na tentativa de reparar o desvio de pênis de bovinos, como fixação do ligamento apical sobre a túnica albugínea (walker, 1980), enxerto autólogo de fáscia lata sob a túnica albugínea (Walker, 1980 e Mobini \& Walker, 1983), transfixação do ligamento à túnica albugínea (Ashdown \& Pearson, 1973), implante de tendão autógeno do músculo flexor (Eurides et al. 2007). Assim como a utilização de de implante de fibra de carbono sobre a túnica albugínea (Mobini et al., 1982), implante de borracha de silicone no corpo cavernoso e entre o ligamento e túnica albugínea (Eurides et al., 1994) e tela de dácron (Boyd \& Hanselka 1972).

Objetivou-se neste experimento promover a correção cirúrgica do desvios de pênis induzido em bovinos, com implante, na extremidade livre do pênis, um segmento autólogo da cartilagem auricular em substituição ao ligamento apical do pênis.

\section{MATERIAL E MÉTODOS}

Foram utilizados 18 novilhos sem raça definida, com idade de 18-24 meses e aparentemente sadios Os novilhos foram observados em monta natural para assegurar a ausência de alterações no instinto sexual ou anomalias no pênis. Após jejum de alimentos sólidos de 24 horas e hídrico de 12 horas foram sedados com cloridrato de xilazina ${ }^{7}$ (0,2mg/kg/peso, IM). Para exposição do pênis foi realizada analgesia epidural caudal com $10,0 \mathrm{~mL}$ de cloridrato de lidocaína a $2 \%$ com adrenalina ${ }^{8}$. Após tricotomia do óstio prepucial e anti-sepsia do pênis e lâmina externa do prepúcio com polivinil-pirrolidona iodo a $10 \%$, foi praticada incisão longitudinal no terço médio da superfície dorsal da extremidade livre do pênis, cerca de $7,0 \mathrm{~cm}$ de comprimento. Foi removido, em média, 6,0 cm do ligamento apical (Eurides \&

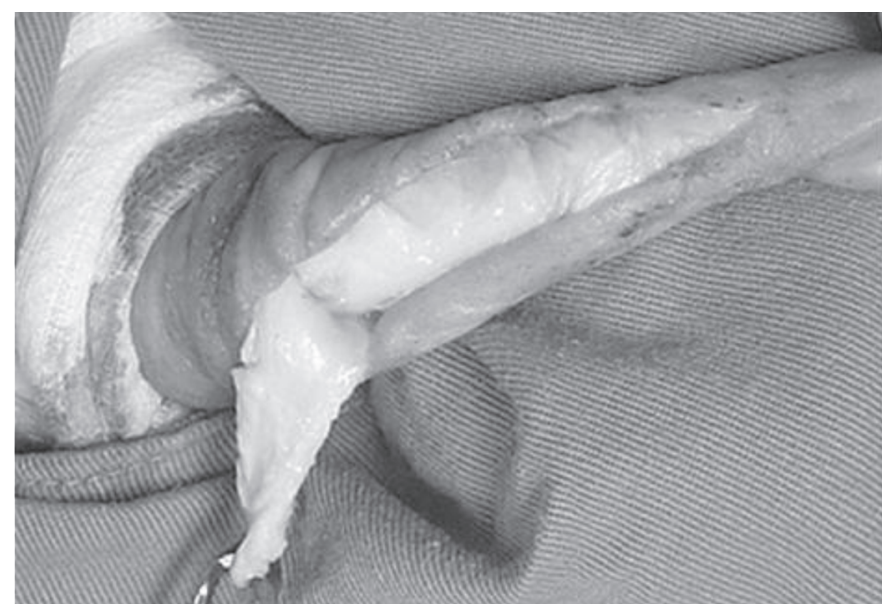

Fig.1. Remoção do ligamento apical na extremidade livre do pênis de bovino sem raça definida.

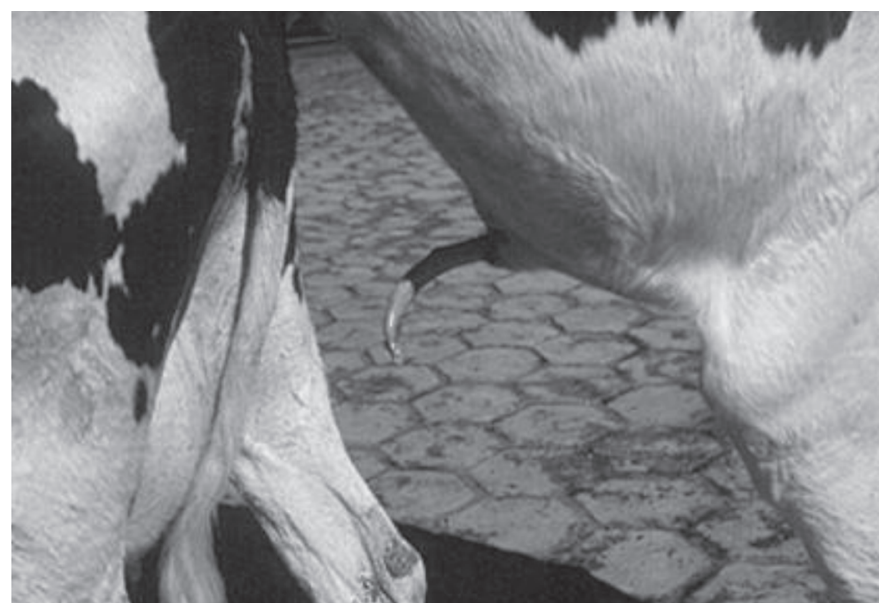

Fig.2. Bovino em monta natural decorrido 60 dias da remoção do ligamento apical do pênis. Observa-se a extremidade livre do pênis desviada ventralmente e para a direita.

Silva 2002), e a pele aproximada com pontos simples separados e fio categute $00^{9}$ (Fig.1)

Decorridos 60 dias os animais foram novamente colocados em presença de fêmeas em estro sendo verificado a formação de desvio ventral e lateral direito do pênis com incapacidade de realizar a cópula (Fig.2).

Após este período os animais foram novamente submetidos ao mesmos métodos pré-operatório e de anestesia, sendo incluído a preparação de um dos pavilhões auriculares. Foram realizados os bloqueios anestésicos do nervo auricular rostrais, nervo auricular caudal, ramos do primeiro e segundo nervos cervicais e ramo auricular interno do nervo facial, que inervam a orelha. Do ápice e no sentido longitudinal do pavilhão auricular, foi removido com bisturi um segmento em forma de "V", iniciando aproximadamente com $2,5 \mathrm{~cm}$ de largura e $14,0 \mathrm{~cm}$ de comprimento. As bordas da cartilagem auricular foram aproximadas com ponto simples contínuo e com fio polivrycril $00^{10}$ e a pele com fio de náilon monofilamentoso ${ }^{11} 00$. A pele

\footnotetext{
${ }^{7}$ Rompun. Bayer do Brasil, São Paulo, SP.

${ }^{8}$ Xylocaína. Astra Química do Brasil, Santo Amaro, SP.

${ }^{9}$ Categute. Laboratório Bruneal. São Bernardo do Campo, SP.

10 Vicryl. Ethicon, São Paulo, SP.
} 


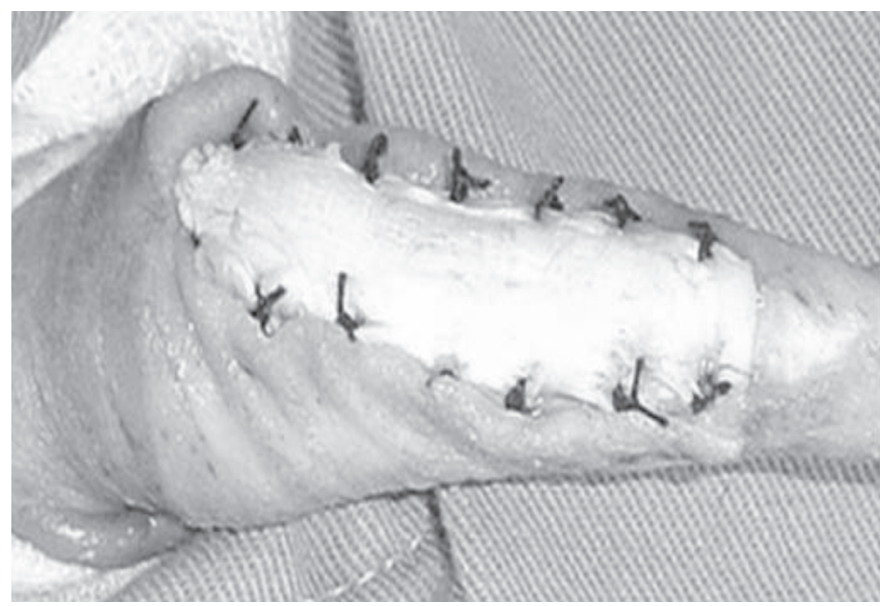

Fig.3. Aspecto da fixação da cartilagem auricular sobre a túnica albugínea peniana com pontos simples separados.

do segmento auricular foi removida sob tração com de pinças hemostáticas. Foi retirado uma tira da cartilagem nas dimensões de aproximadamente $8,0 \mathrm{~cm}$ de comprimento por $1,0 \mathrm{~cm}$ de largura e mantida em frasco fechado com solução fisiológica a $0,9 \%$ na temperatura ambiente até o momento do implante.

Foi praticado uma incisão longitudinal de aproximadamente $8,0 \mathrm{~cm}$ de comprimento na superfície dorsal da glande, começando entorno de $1,0 \mathrm{~cm}$ da extremidade caudal do colo da glande e terminando a $1,0 \mathrm{~cm}$ da inserção da lâmina interna do prepúcio. A cartilagem foi implantada sobre a túnica albugínea com pontos simples separados e fio de algodão $00^{12}$ (Fig.3) e a pele com categute $00^{9}$, através de pontos simples separados.

No pós operatório (PO) foi administrada enrofloxacina ${ }^{13}$ $(2,5 \mathrm{mg} / \mathrm{kg} / \mathrm{dia}, \mathrm{IM})$, durante seis dias e curativos diários com lavagens da cavidade prepucial com solução fisiológica 0,9\% e infusão de polivinil-pirrolidona ${ }^{14}$ a $2 \%$. A ferida do pavilhão auricular foi diariamente limpa com solição fisiológica $0,9 \%$, aplicado polivinil-pirrolidona e coberta com gaze e fixada com esparadrapo. Os pontos de pele foram retirados decorridos 15 dias de PO.

Após 45 dias de PO foram separados, por sorteio, seis bovinos que foram submetidos ao mesmo protocolo préoperatório e anestésico para amputação da extremidade livre do pênis (Eurides \& Silva 2002). Foram realizados estudos macroscópicos da integração tecidual cartilagem auricular com a túnica albugínea, e coleta de fragmentos do pênis com a carilagem para observação em microscopia de óptica. Os animais depois de recuperados foram encaminhados para abate em frigorífico. Os outros permaneceram em observação durante 120 dias, período quando foram avaliados em presença de fêmeas em estro e submentos a amputação da extremidade livre do pênis para avaliação histológica.

Os fragmentos foram mantidos em solução aguosa de formol a $10 \%$ e destas, obtiveram-se cortes histológicos corados com hematoxilina eosina (HE) (Luna 1968), e Tricômio de Masson

\footnotetext{
${ }^{11}$ Nylon 8-0. Polysuture Indústria e Comércio, São Sebastião do Paraíso, MG. Brasil.

${ }^{12}$ Algodão branco A. Laboratório Bruneau, São Bernardo do Campo, SP.

${ }^{13}$ Baytril. Bayer do Brasil, São Paulo, SP.

${ }^{14}$ Furacim solução. Schering-Plough, Rio de Janeiro, R.J.
}

(TM). Ao exame histológico pesquisou-se a resposta tecidual na presença da cartilagem auricular.

\section{RESULTADOS E DISCUSSÃO}

Foi demonstrado por Ashdown \& Pearson (1971) e Eurides et al. (1992) que a secção cirúrgica do ligamento apical de touros ocasionou formação de desvio ventral e lateral direito durante a ereção do pênis. Nestes tipos de desvios, como o provocado neste experimento, o enxerto de cartilagem auricular autóloga sobre a túnica albugínea foi suficiente para corrigir o desvio devido a presença do implante e a formação de tecido conjuntivo fibroso e firas colágenas.

Verificou-se que a presença da cartilagem auricular entre sobre a túnica albugínea ocasional a formação de tecido conjuntivo fibroso, com firme aderência fibrosa da cartilagem, túnica albugínea e ligamento apical, como referido por Eurides et al. (1994). A cartilagem implantada e a aderência formada pode impedir o deslocamento do ligamento apical para o lado esquerdo, evitando a formação de desvio em espiral. Provavelmente o implante somado as aderência fibrosas podem ajudar na sustentação ereta do pênis durante a realização da cópula.

Foi promovido por Walker (1980) a formação de duas faixas do ligamento apical para impedir seu deslizamento sobre o dorso do pênis para corrigir desvio em espiral. A técnica é de difícil e demorada aplicação devido a constituição densa do ligamento e da túnica albugínea. As mesmas observações podem ser feitas quando da aplicação da técnica descrita por Mobini \& Walker (1983), que utilizaram um segmento autólogo de fáscia lata sobre ao ligamento. Neste trabalho, a liberação do ligamento apical da túnica albugínea foi facilitado devido a presença de tecido conjuntivo frouxo no terço médio da extremidade livre do pênis. Os procedimentos cirúrgicos utilizados podem impedir o deslizamento do ligamento sobre a túnica albugínea e melhorar a capacidade de sustentação devido a presença da cartilagem auricular e da formação de tecido conjuntivo fibroso envolvendo a túnica albugínea, implante e ligamento apical.

Decorridos 120 dias da aplicação do implante observou-se presença de tecido conjuntivo fibroso suficiente para envolver a túnica albugínea e o implante, resultados semelhantes aos verificados por Mobini et al. (1982) com ficação de fibra de carbono. Após este período, os animais quando em presença de fêmeas em estro, apresentavam bom comportamento sexual, capacidade de exposição de pênis, ausência de desvio ventral e lateral direito e realização da cópula (Fig.4).

Foram descritas a técnicas cirúrgicas para correção de desvio de pênis como implante de prótese de dácron (Boyd \& Hanselka 1972), de fibra de carbono (Mobini et al. 1982) e de silicone no corpo cavernoso e sobre a túnica albugínea (Eurides et al. 1994). Os métodos apresentam os mesmos objetivos da técnica descrita neste experimento, no que se refere a proporcionar melhor sustentação do pênis durante a realização da cópula. O implante 


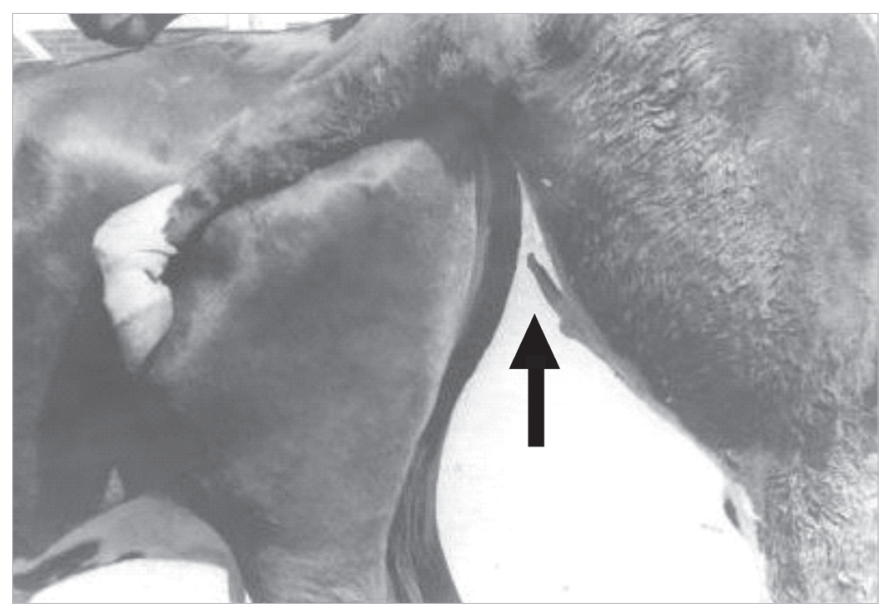

Fig.4. Bovino em monta natural decorrido 120 dias da remoção do ligamento apical do pênis. Observa-se a extremidade livre do pênis com ausência de desvio (seta).

de materiais inorgânicos para corrigir desvios de pênis, como o drácron (Boyd \& Hanselka 1972), fibra de carbono (Mobini et al. 1982) e silicone (Eurides et al. 1994), apesar de provocarem mínima reação inflamatória e integrarem aos tecidos circunvizinhos, apresentam maiores possibilidades de ocasionarem reações locais indesejáveis. Fato que não foi verificado neste experimento com enxerto autólogo de cartilagem auricular.

Aos 120 dias de PO, o enxerto permaneceu em bom estado de conservação, sem divisão celular e não apresentou ao exame histológico sinais de rejeição. A ausência de complicações constitui uma das vantagens do método cirúrgico empregado, pois o enxerto, mesmo desprovido de vascularização e suprimento sangüíneo próprio, integrou-se tanto à túnica albugínea como ao ligamento apical

Para corrigir desvio de pênis de bovinos foi empregado o fio de náilon na síntese de tela de dácron (Boyd \& Hanselka 1972) na transfixação do ligamento apical à túnica albugínea (Ashdown \& Pearson (1973). O fio categute foi utilizado para fixar o ligamento em forma de faixas sobre a túnica albugínea (Walker 1980), assim como para aproximar o implante de fibra de carbono sobre a túnica albugínea (Mobini et al. 1982). Foi recomendado, no entanto, por Morbini \& Walker (1983) o uso do fio de ácido poliglicólico para implante de fáscia lata. O emprego de fio inabsorvível, como utilizado neste experimento é vantajoso por manter o enxerto firmemente fixado á túnica albugínea e ligamento apical por um longo período de tempo (Eurides 1994).

A disfunção do ligamento apical do pênis está ligada a sua pouca adesão à túnica albugínea (Mobini et al. 1982, Eurides et al. 1994). O que morfologicamente é de se esperar, uma vez que esta adesão se faz por tecido conjuntivo frouxo. A substituição deste tecido por tecido conjuntivo denso ocasiona aderência do ligamento. Fato verificado nesse experimento, onde a substituição do ligamento apical do pênis por segmento de cartilagem auricular autóloga favoreceu a troca do tecido conjuntivo frouxo por espesso tecido conjuntivo denso, junto à túnica albugínea. Implantes de materiais biológicos têm sido utilizados com finalidade de constituir molde ou arcabouço para o desenvolvimento de tecidos próprios do receptor, que poderão permanecer no leito receptor durante tempo indefinido (Gabrielli, 1986). Neste trabalho, notou-se que o processo inflamatório ocorrido na intimidade do enxerto se caracterizou pela formação de tecido de granulação, presença de fibroblastos, grande quantidade de vasos sanguíneos e fibras colágenas neoformadas, ou seja, intensa atividade de fibroplasia, sem sinais de regeição (Fig.5).

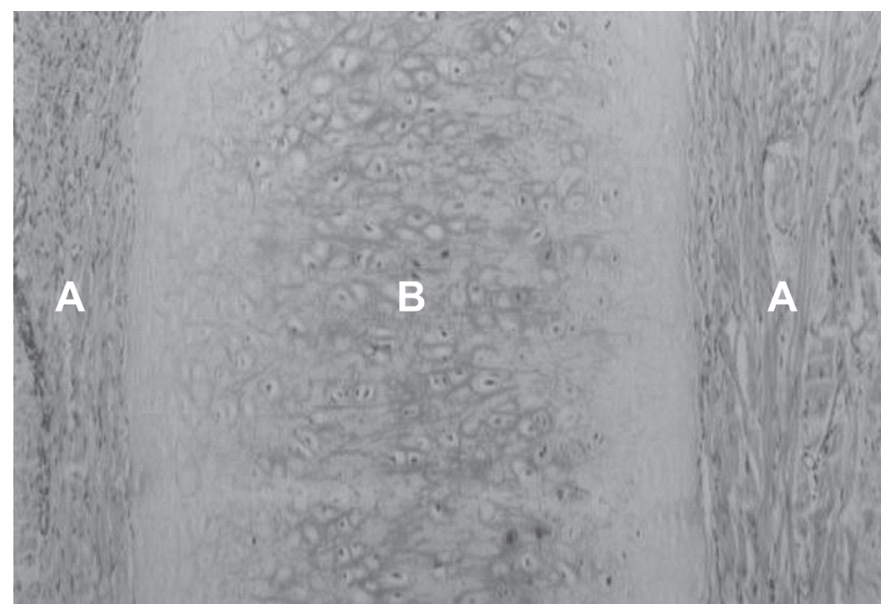

Fig.5. Aspecto histológico da extremidade livre do pênis de bovino com enxerto de segmento de cartilagem auricular autóloga sobre a túnica albugínea aos 45 dias de PO. Notase intensa fibroplasia (A), com tecido de granulação envolvendo a cartilagem implantada (B). HE, 400x.

A força de tensão de um tecido pode estar diretamente proporcional a intensidade de colágeno e o tecido de granulação se transforma em cicatriz composta de fibroblastos fusiformes, colágeno denso, fragmentos de tecido elástico e outros componentes da matriz extra celular (Cotran et al. 2000). Assim, neste experimento, a cartilagem implantada serviu como condutor de fibras colágenas. Entretanto, devido aos momentos de observações, não foi avaliado período de permanência do enxerto no leito receptor.

\section{CONCLUSÕES}

A cartilagem auricular autóloga implantada sobre a túnica albugínea em pênis de bovino é envolvida por tecido conjuntivo fibroso, ocasiona pouca reação inflamatória, intensa fibroplasia com aderência resistente na túnica albugínea.

A ausência de reações locais indesejáveis com enxerto de cartilagem auricular autóloga e a correção de desvio de pênis ventral e lateral direito, demonstra ser este procedimento clinicamente conveniente.

O uso do fio de algodão foi eficaz por manter a cartilagem bem fixada à túnica albugínea e ligamento apical por um longo período de tempo. 
A cartilagem auricular autóloga promove sustentação ereta do pênis durante a cópula sem modificação da libido, e corrige os desvios ventral e lateral direito, sendo procedimento cirúrgico eficaz.

Agradecimentos.- Ao Conselho Nacional de Desenvolvimento Científico e Tecnológico (CNPq), pela contribuição financeira que permitiu a realização desse experimento.

\section{REFERÊNCIAS}

Arthur G.H. 1979. Reprodução e obstetrícia em veterinária. $4^{a}$ ed. Guanabara Koogan, Rio de Janeiro. 573p.

Ashdown R.R. \& Peasrson H. 1971. The functional significance of the dorsal apical ligament of the bovine penis. Res. Vet. Sci. 12:183-184.

Ashdown R.R. \& Peasrson H. 1973. Studies on "Corkscrew" in the bull. Vet. Rec. 93:30-35.

Boyd C.L. \& Hanselka D.V. 1972. Implantation of a silicone prosthesis for corretion of bovine desviation. J. Am. Vet. Assoc. 161(3):275-277.

Eurides D., Contesini E.A. \& Viana S.M. 1992. Preparação de rufiões bovinos por remoção do ligamento apical do pênis. Ciência Rural 22(2):85-189.

Eurides D., Silva M. \& Contesini E.A. 1994. Implante de borracha de silicone em pênis de bovinos. Estudo experimental. Ciência Rural 24(3):545-550.

Eurides D., Silva L.A.F., Fioravanti M.C., Chaves N.S.T., Campos V.A., Severino R.S., Mazzanti A., Gonçalves G.F. \& Teixeira L.H.G. 1998. Aspectos morfológicos e morfométricos do ligamento apical do pênis de bovinos da raça Nelore. Ars Vet. 14(2):116-120.

Eurides D., Bento L.R., Silva C.R., \& Daleck C.R. 2007. Implantation of the autologous tendon from the superficial flexor of the fingers muscle in the deviation repair of bovine penis. Braz. J. Vet. Res. Anim. Sci. 44(6):415-421.

Eurides D. \& Silva L.A.F. 2002. Métodos de preparo de rufiões bovinos e eqüinos. Talento, Goiânia. 112p.

Luna L.G. 1968, Manual of Histologic Staning Methods of the Armed Forces Institute of Pathology. $3^{\text {rd }}$ ed. McGraw Hill, New York. 258p.

Mobini S., Walker D.F. \& Grawley R.R. 1982. An experimental evalualtion of the respnse of the bull penis to carbon fibigir implants.Cornell Vet. 72:350-360.

Mobini S. \& Walker D.F. 1983. Desviation of the penis in the bull. Compend. Cont. Educ. Pract. Vet. 5(5):280-284,

Roberts S.J. 1979. Obstetricia Veterinaria y Patologia de la Reproduction. Editorial Hemisfério Sur, Buenos Aires. 1020p.

Walker D.F. 1980. Penile surgery in the bovine. Part III. Med. Vet. Pract. 61(1):69-71. 